\title{
Behavior of Axially Loaded Concrete Wall Panels with Openings: An Experimental Study
}

\author{
S. Fragomeni ${ }^{1, *}{ }^{*}$, J.H. Doh ${ }^{2}$ and D.J. Lee ${ }^{3}$ \\ ${ }^{1}$ School of Engineering and Science, Victoria University, Australia \\ ${ }^{2}$ School of Engineering, Griffith University Gold Coast Campus, Australia \\ ${ }^{3}$ School of Construction Engineering, Seoul National University of Technology, Korea
}

(Received: 6 April 2011; Received revised form: 2 November 2011; Accepted: 7 November 2011)

\begin{abstract}
Forty seven reinforced concrete walls with various opening configurations are tested in both one-way and two-way action. The test panels, with a slenderness ratio of 30,35 or 40 , were subjected to a uniformly distributed axial load at an eccentricity of one sixth of the wall thickness $\left(t_{w} / 6\right)$. Apart from highlighting the experimental set-up; typical crack patterns, failure modes, and load-deflection behaviour of test panels are also reported. Actual test failure loads are compared to ultimate load predictions using the Australian standard wall design equation and also a recently derived formula specifically for walls with openings. The code equation is found to be inadequate for the many cases investigated whereas the derived formula was verified as being adequate in predicting failure load of walls with openings.
\end{abstract}

Key words: concrete walls, openings, axial load, code method, slenderness ratio, design equation.

\section{INTRODUCTION}

Reinforced concrete walls with eccentric axial loads can be designed using code methods that include the use of simplified formulae or the more accurate column design procedure. In many cases more rigorous methods such as utilising finite element analysis can also be employed. The design of walls as structural members is now just as significant as beams, slabs and columns. This is due to the modern day popularity of tilt-up construction, shear walls and concrete cores in tall buildings. The popularity has spread to Australia where prior to the 1990's limited experimental research was performed on concrete wall panels. More recently, significant research projects focusing on the load capacity of solid concrete walls that have been undertaken in Australia include the work of Fragomeni (1995), Sanjayan and Maheswaran (1999) and Doh (2002). Since then introductory research was undertaken by Doh and Fragomeni (2006) on the load capacity of walls with openings, which was the catalyst for the extensive experimental study by Lee (2008) on the same topic.

The design of walls with openings is given little treatment in international codes of practise. When designing such elements engineering practitioners make the decision to divide the wall into segments of columns connected by cross beams at openings, which then requires the design of each individual segment. Although this is quite acceptable, it would be more convenient if the practitioner was provided with simplified equations similar to those provided in the Australian Standard AS3600-2001 and American Concrete Institute code ACI318-2008 for solid load bearing walls supported top and bottom only. As highlighted by Doh and Fragomeni (2005), these code methods can only be used if certain restrictions are met. The simplified design is restricted to normal strength concrete walls with slenderness ratios of less than 30

*Corresponding author. Email address: sam.fragomeni@vu.edu.au; Fax: + 61-3-9919-4908; Tel: +61-3-9919-5212.

Associate Editor. J.G. Dai. 
and generally cannot account for openings such as doors or windows. In the applications highlighted in the previous paragraph, concrete walls with varying support conditions, higher slenderness ratios and higher concrete strengths are commonly used which are outside the restrictions of current formulae; therefore more guidance in this range was desired. Significantly, the newly released Australian Concrete Standard, AS36002009 , has provided extended rules for the use of the simplified wall design equation for walls supported on either two, three or four sides, and for walls with higher concrete strengths. There are also limited provisions for walls with small openings.

As adapted previously from Doh and Fragomeni (2006), a wall with one opening behaving in one-way action and two-way action is depicted in Figure 1. Side supports create the double curvature scenario in both parallel and perpendicular directions. The ideal cracking scenarios at high axial loads are also depicted. The appearance of openings can have an effect on the load capacity and cracking regime and is a focus of this paper.

Many researchers have investigated the behaviour of reinforced concrete solid walls either in one-way or twoway action. An extensive review of the previous work undertaken in this area is given elsewhere (Doh et al. 2001; Doh and Fragomeni 2005). The later paper provided results of axial load tests on solid walls with slenderness ratios between 25 and 40, a study that provided an alternative simplified equation to the codes for load bearing walls with slenderness in this range. Only a few studies involved walls with openings. Apart from the introductory work of Seddon (1956) on walls

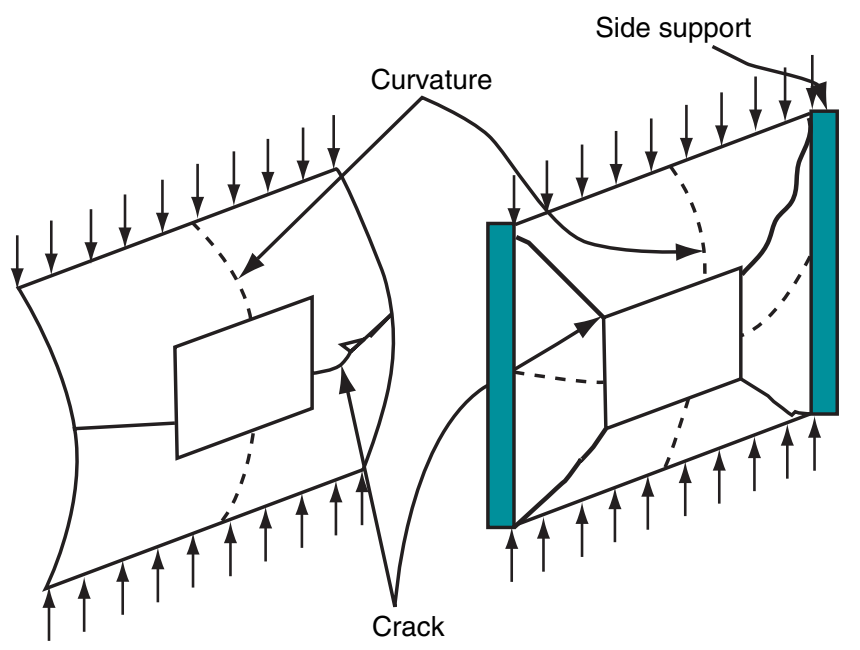

(a) One-way action wall with opening

(b) Two-way action wall with opening

Figure 1. Walls with and without side supports (Doh and Fragomeni 2006) with openings, Saheb and Desayi (1990) carried out a number of tests on walls with openings in both one and two-way action. However, the slenderness ratio $\left(H / t_{w}\right)$ of the panels was low at 12 .

Due to the fact that there was minimal experimental data on walls with openings an extensive experimental program was recently undertaken by Lee (2008). The main objective of this paper is to investigate the behaviour of axial loaded walls by evaluating the results of this extensive experimental study on walls with openings. Details of the walls tested that include experimental setup and loading regime, failure loads, typical crack patterns and load-deflection characteristics are provided. The forty seven half-scale panels were tested in one and two-way action with slenderness ratios between 30 and 40 . Utilising these test results, a previously derived formula by Doh and Fragomeni (2006) predicting the ultimate load of walls with openings is verified.

\section{SIMPLIFIED WALL DESIGN USING AS3600-2009}

In Australia, the design of reinforced concrete walls is undertaken using the guidelines given in the Concrete Standard (AS3600-2009). The standard provides for a simplified equation to calculate the axial load capacity of walls when certain loading and bracing restrictions are met or alternatively allows for any wall to be designed using the column provisions. Although higher capacities can be obtained using the column method, a minimum vertical reinforcement content of $1 \%$ placed in two layers is required.

For the simplified design method, the ultimate design axial strength per unit length (in $\mathrm{N} / \mathrm{mm}$ ) of a braced wall in compression is given by the following formula.

$$
\phi N_{u}=\phi\left(t_{w}-1.2 e-2 e_{a}\right) 0.6 f_{c}^{\prime}
$$

where $t_{w}$ is the wall thickness $(\mathrm{mm}), e$ is the load eccentricity $(\mathrm{mm})$ which has a minimum of $0.05 t_{w}$, $f_{c}^{\prime}(\mathrm{MPa})$ is concrete strength and $e_{a}=H_{w e}{ }^{2} /\left(2500 t_{w}\right)$. $H_{w e}$ is the effective height of the wall. The strength reduction factor $\phi$ is 0.6 . The walls are required to have minimum reinforcement ratios of 0.0015 vertically, $\rho_{v}$ and 0.0025 horizontally, $\rho_{h}$.

Eqn 1 is the same as in the previous code, AS36002001, except that its scope has been extended for higher strength concrete, $20 \leq f_{c}^{\prime} \leq 100 \mathrm{MPa}$. It applies to walls where the slenderness ratio, $H_{w e} / t_{w} \leq 30$. The effective height $\left(H_{w e}=k H_{w}\right)$ clause has been re-written to include walls supported on two, three and four sides. That is the $k$ factor is given as follows:

a) For One-way buckling with floors providing lateral support at both ends 
$k=0.75$ when walls are restrained against rotation at both ends, and

$k=1.0$ when walls are not restrained against rotation at one or both ends.

b) For Two-way buckling with three side lateral support provided by floors \& intersecting walls $k=\frac{1}{1+\left(H_{w} / 3 L\right)^{2}} \geq 0.3$ but less than obtained from $a$ ).

c) For Two-way buckling with four side lateral support provided from floors \& intersecting walls

$k=\frac{1}{1+\left(H_{w} / L\right)^{2}}$ for $H_{w} \leq L$ or $k=\frac{L}{2 H_{w}}$ for $H_{w}>L$

where for all items, $H_{w}$ is the floor-to-floor unsupported height and $L$ is the horizontal length.

The equation was recently found to perform adequately for a range of solid wall panels previously tested with two, three and four sides supported (Fragomeni and Doh (2010)).

Significantly AS3600 allows the effects of openings in a wall supported on four sides (two-way action) to be ignored if the total area of openings is less than 1/10 of the area of the wall, and the height of any opening is less than $1 / 3$ of the height of the wall. In this instance the simplified design equation can be used as normal ignoring the opening(s). If these conditions are not satisfied the area of wall between opening and support shall be designed as supported on three sides, or the area between two openings shall be designed as supported on two sides.

\section{WALL DESIGN FORMULAE FOR WALLS WITH OPENINGS}

\subsection{Saheb and Desayi (1990) Formula for Walls with Openings}

For wall panels with openings, Saheb and Desayi (1990) proposed that the ultimate load is:

$$
P_{u o}=\left(k_{1}-k_{2}\right) P_{u}
$$

where

$P_{u}$ is the ultimate load of an identical one-way and two-way solid wall panel defined as $0.55\left[A_{g} f_{c}^{\prime}+\left(f_{y}-f_{c}^{\prime}\right) A_{s v}\right]\left\{1-\left[H /\left(32 t_{w}\right)\right]^{2}\right\}$ and $0.67 f^{\prime} A_{g}$ $\left\{1-\left[L /\left(120 t_{w}\right)\right]^{2}\right\}\{1+0.12(H / L)\}$ respectively. $k_{1}$ and $k_{2}$ were respectively, obtained from the test results, 1.25 and 1.22 for one-way action and 1.02 and 1.00 for twoway action.

Figure 2 identifies the important symbols used where $G_{1} \& G_{2}=$ centres of gravity of wall cross section with

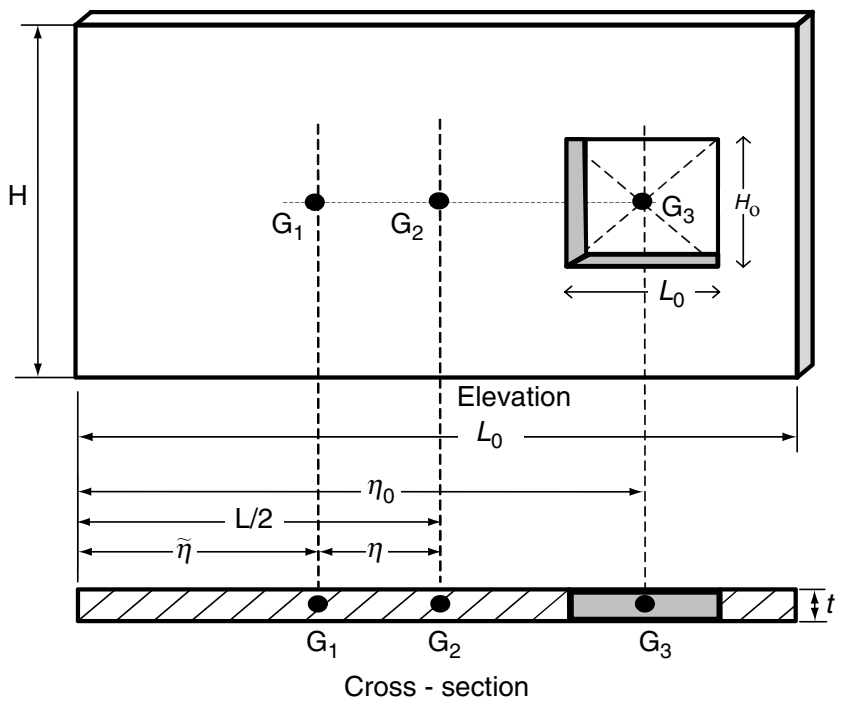

Figure 2. Geometry of wall openings in elevation and cross-section plan (Saheb and Desayi 1990)

and without opening, respectively; $G_{3}=$ centre of gravity of the opening. The non-dimensional quantity $\chi=\left(\frac{A_{o}}{A}+\frac{\eta}{L}\right)$ in which $\eta=\left(\frac{L}{2}-\bar{\eta}\right)$ with $\bar{\eta}$ being the distance from the left vertical edge to the centre of gravity of the cross-section of the panel with openings, or $\bar{\eta}=\left(\frac{\frac{1}{2} t_{w} L^{2}-t_{w} L_{o} \eta_{o}}{L t_{w}-L_{o} t_{w}}\right)$ and, $A_{o}=L_{o} t_{w}$.

Eqn 2 is only applicable to concrete walls with slenderness ratio $H / t_{w}<12$ and normal strength concrete, relating to the test data from which they were derived. Beyond this slenderness ratio or for high strength concrete panels, the formulas may lead to inaccurate predictions (Doh and Fragomeni 2006).

\subsection{Doh and Fragomeni (2006) Formula for Walls with Openings}

Doh and Fragomeni (2006) conducted tests on 8 normal strength concrete wall panels with openings in one-way and two-way action with slenderness ratios $\left(H / t_{w}\right)$ of 30 or 40 . The results were examined along with identically sized solid panels tested by Doh (2002).

For panels with openings, the authors proposed that the ultimate load for panels with openings is given by:

$$
N_{u o}=\left(k_{1}-k_{2} \chi\right) N_{u}
$$

where

$N_{u}$ is the ultimate load of an identical one-way and two-way solid wall panel defined as $N_{u}=2.0 f_{c}^{\prime 0.7}\left(t_{w}-\right.$ $1.2 e-2 e_{a}$ ) which is a modified version of the AS3600 equation and intended for panels with high slenderness ratios. 
$e_{a}=H_{w e}{ }^{2} /\left(2500 t_{w}\right)$ as before with $H_{w e}=\beta H$
$\beta=1$ for $H / t_{w}<27$, and $\beta=18\left(\frac{H}{t_{w}}\right)^{0.88}$ for $H / t_{w} \geq 27$ when in one-way action,

$$
\beta=\alpha \frac{1}{1+(H / L)^{2}} \text { for } H \leq L \text {, and } \beta=\alpha \frac{L}{2 H} \text { for } H>L
$$

when in two way action

In these equations, the eccentricity parameter

$$
\begin{aligned}
& \alpha=\frac{1}{1-\frac{e}{t_{w}}} \text { for } H / t_{w}<27 \text { and } \alpha=\frac{1}{1-\frac{e}{t_{w}}} \times \frac{18}{\left(\frac{H_{w}}{t_{w}}\right)^{0.88}} \\
& \text { for } H / t_{w} \geq 27 .
\end{aligned}
$$

$k_{1}$ and $k_{2}$ were respectively, obtained from the test results, 1.175 and 1.188 for one-way action and 1.004 and 0.933 for two-way action.

The non-dimensional quantity $\chi=\left(\frac{A_{O}}{A}+\frac{\eta}{L}\right)$ is as defined by Saheb and Desayi (1990) and described in Section 3.1.

Doh and Fragomeni (2006) found that Eqn 3 gave a good prediction of the 8 test panel failure loads. Also when compared with Saheb and Desayi's (1990) test data, Eqn 3 was found to give reasonably accurate prediction. Despite the positive results obtained it was evident that more testing was required on walls with various opening configurations, and walls with higher strength concrete for further verification.

\section{TEST SPECIMENS AND TEST SET UP}

Due to the limited nature of the previously derived Eqn 3, Lee (2008) undertook an extensive experimental study on walls with various opening configurations, concrete strengths and slenderness ratios.

\subsection{Test Panels}

In the major part of the experimental program, thirty five half-scale reinforced concrete wall panels with openings were tested to failure. Typical details of the test panels with one and two openings are given in Figure 3. The dimensions and material properties of the test panels are given Table 1, where $O$ and $T$ indicate one and two-way action tests respectively. The two digits after this first letter denote the nominal concrete strength, followed by W1 or W2 denoting one or two window openings respectively. The final part of the panel description refers to location and length of panel, so $\mathrm{C} 1.6$ refers to centre opening for $1.6 \mathrm{~m}$ long panel.

All wall panels were reinforced with a single F41 mesh, placed centrally within the panel cross-section. The F41 mesh had design yield strength of $450 \mathrm{MPa}$ and the minimum tensile strength was $500 \mathrm{MPa}$. The
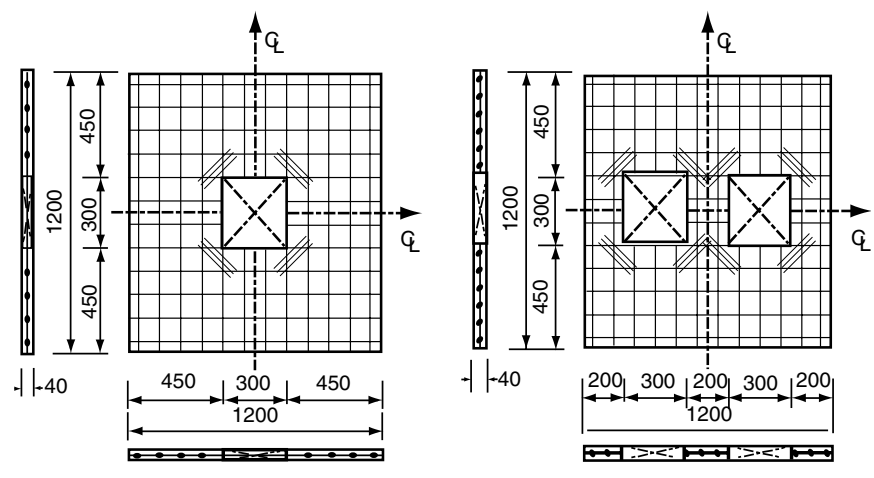

Figure 3. Details of typical test wall panels with one and two openings (dimensions in $\mathrm{mm}$ )

reinforcement ratios $\rho_{v}$ and $\rho_{h}$ were 0.0031 for all panels, satisfying the minimum requirements in the Australian Standard. Reinforcing was also placed diagonally in each corner of the openings to prevent shrinkage cracking. This consisted of strips cut from F41 mesh. Three of these strips were tied in each corner. The length of each strip was the same as the dimension of the side of the opening; $300 \mathrm{~mm}$ for the small walls and $400 \mathrm{~mm}$ for the larger walls. The fixing and the layout of the corner reinforcement are also shown in Figure 3. As current simplified wall design equations only require minimum reinforcement, it was decided that investigating the effect of increasing reinforcement ratios would not be investigated. Obviously increasing the amount of reinforcement, particularly over $1 \%$, and in two layers would contribute significantly to load capacity. Codes of practice such as AS3600 (2009) suggest the use of the column design method in such cases.

The concrete was supplied by a local concrete readymix company. General purpose cement, sand and $10 \mathrm{~mm}$ aggregates were used to produce concrete. No admixtures were used for the normal strength mixes. The typical high strength concrete mixes consisted of fly ash, water reducing agent and super-plasticiser in addition to the major components. Wall panels were cast horizontally in specially made timber moulds with reinforcement secured at the centre cross-section with wire ties on $20 \mathrm{~mm}$ high chairs, as shown in Figure 4. High density polystyrene foam was placed in specific positions on the timber moulds to ensure openings were formed in places required. This material was used for the openings as it could easily be cut to the required size of the openings needed and could also be easily removed before testing of the wall panels. Three moulds were made reflecting the three different sized panels being investigated.

Wall panels were general cast in batches of three, to maximise the usage of moulds and concrete delivered. 
Table 1. Wall panel dimensions, concrete strengths, failure loads

\begin{tabular}{|c|c|c|c|c|c|c|c|}
\hline $\begin{array}{l}\text { Panel } \\
\text { designation }\end{array}$ & $\begin{array}{l}\text { Size of panel } \\
H \times L \times t_{w}(\mathrm{~mm})\end{array}$ & $\begin{array}{c}\text { Opening size } \\
H_{0} \times L_{0} \times n(\mathrm{~mm})\end{array}$ & $H / t_{w}$ & $\begin{array}{l}\text { Cure } \\
\text { (days) }\end{array}$ & $\begin{array}{c}\boldsymbol{f}_{c m} \\
(\mathrm{MPa})\end{array}$ & $\begin{array}{c}N_{u, t e s t} \\
(\mathbf{k N})\end{array}$ & $\begin{array}{l}N_{u . t e s t} \\
f_{c}^{\prime} L_{e f f} t_{w}\end{array}$ \\
\hline O50W1C1.2 & \multirow[t]{4}{*}{$1200 \times 1200 \times 40$} & \multirow[t]{4}{*}{$300 \times 300 \times 1$} & \multirow[t]{4}{*}{30} & 45 & 53.0 & 309.0 & 0.162 \\
\hline O70W1C1.2 & & & & 28 & 67.7 & 426.7 & 0.175 \\
\hline O90W1C1.2 & & & & 55 & 95.1 & 470.9 & 0.138 \\
\hline O95W1C1.2 & & & & 49 & 96.2 & 488.5 & 0.141 \\
\hline O45W1C1.4 & \multirow[t]{3}{*}{$1400 \times 1400 \times 40$} & \multirow[t]{3}{*}{$350 \times 350 \times 1$} & \multirow[t]{3}{*}{35} & 36 & 38.0 & 191.3 & 0.120 \\
\hline O90W1C1.4 & & & & 45 & 80.0 & 300.2 & 0.089 \\
\hline O95W1C1.4 & & & & 57 & 99.3 & 426.1 & 0.102 \\
\hline O50W1C1.6 & \multirow[t]{2}{*}{$1600 \times 1600 \times 40$} & \multirow[t]{2}{*}{$400 \times 400 \times 1$} & \multirow[t]{2}{*}{40} & 30 & 47.0 & 294.3 & 0.130 \\
\hline O90W1C1.6 & & & & 45 & 97.1 & 503.3 & 0.108 \\
\hline O50W2C1.2 & \multirow[t]{3}{*}{$1200 \times 1200 \times 40$} & \multirow[t]{3}{*}{$300 \times 300 \times 2$} & \multirow[t]{3}{*}{30} & 30 & 50.3 & 191.3 & 0.158 \\
\hline O70W2C1.2 & & & & 28 & 67.7 & 242.8 & 0.149 \\
\hline O95W2C1.2 & & & & 49 & 96.2 & 308.1 & 0.133 \\
\hline O45W2C1.4 & \multirow[t]{3}{*}{$1400 \times 1400 \times 40$} & \multirow[t]{3}{*}{$350 \times 350 \times 2$} & \multirow[t]{3}{*}{35} & 47 & 44.5 & 150.7 & 0.120 \\
\hline O90W2C1.4 & & & & 45 & 80.0 & 244.3 & 0.109 \\
\hline O95W2C1.4 & & & & 57 & 99.3 & 350.8 & 0.126 \\
\hline O50W2C1.6 & \multirow[t]{3}{*}{$1600 \times 1600 \times 40$} & \multirow[t]{3}{*}{$400 \times 400 \times 2$} & \multirow[t]{3}{*}{40} & 30 & 51.1 & 195.7 & 0.120 \\
\hline O70W2C1.6 & & & & 61 & 74.1 & 279.0 & 0.118 \\
\hline O90W2C1.6 & & & & 45 & 97.1 & 347.3 & 0.112 \\
\hline T50W1C1.2 & \multirow[t]{2}{*}{$1200 \times 1200 \times 40$} & \multirow[t]{2}{*}{$300 \times 300 \times 1$} & \multirow[t]{2}{*}{30} & 29 & 50.3 & 706.3 & 0.390 \\
\hline T70W1C1.2 & & & & 54 & 74.1 & 953.5 & 0.361 \\
\hline T45W1C1.4 & \multirow[t]{3}{*}{$1400 \times 1400 \times 40$} & \multirow[t]{3}{*}{$350 \times 350 \times 1$} & \multirow[t]{3}{*}{35} & 49 & 45.5 & 732.8 & 0.383 \\
\hline T90W1C1.4 & & & & 55 & 95.1 & 1303.7 & 0.326 \\
\hline T95W1C1.4 & & & & 44 & 96.2 & 1298.4 & 0.321 \\
\hline T50W1C1.6 & \multirow[t]{3}{*}{$1600 \times 1600 \times 40$} & \multirow[t]{3}{*}{$400 \times 400 \times 1$} & \multirow[t]{3}{*}{40} & 29 & 50.3 & 1030.1 & 0.427 \\
\hline T70W1C1.6 & & & & 91 & 75.1 & 1390.6 & 0.386 \\
\hline T90W1C1.6 & & & & 48 & 93.6 & 1583.3 & 0.352 \\
\hline T50W2C1.2 & $1200 \times 1200 \times 40$ & $300 \times 300 \times 2$ & 30 & 32 & 50.3 & 618.0 & 0.512 \\
\hline T70W2C1.2 & & & & 54 & 74.1 & 633.4 & 0.356 \\
\hline T90W2C1.2 & & & & 49 & 97.1 & 665.1 & 0.285 \\
\hline T45W2C1.4 & $1400 \times 1400 \times 40$ & $350 \times 350 \times 2$ & 35 & 48 & 45.5 & 662.2 & 0.520 \\
\hline T90W2C1.4 & & & & 55 & 95.1 & 918.2 & 0.345 \\
\hline T95W2C1.4 & & & & 55 & 80.0 & 759.9 & 0.339 \\
\hline T50W2C1.6 & $1600 \times 1600 \times 40$ & $400 \times 400 \times 2$ & 40 & 20 & 50.3 & 647.5 & 0.336 \\
\hline T70W2C1.6 & & & & 91 & 75.1 & 988.8 & 0.411 \\
\hline T90W2C1.6 & & & & 30 & 94.2 & 1236.1 & 0.410 \\
\hline
\end{tabular}

- $n$ is number of openings.

- *Effective length, $L_{e f f}=L-L_{o}$ where $L_{o}$ is length of opening(s).

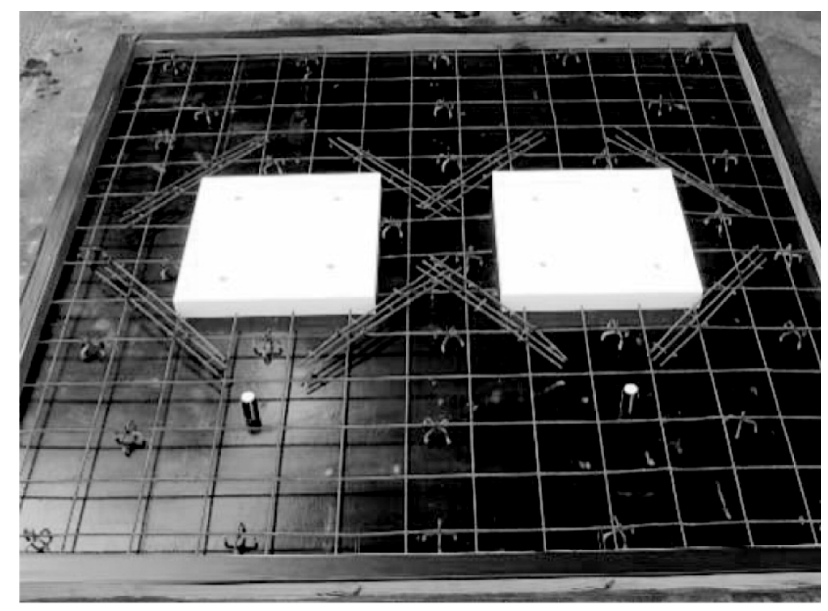

Figure 4. Actual formwork and steel reinforcement set-up
For each wall panel cast a minimum of three cylinders were also produced. The delivered concrete was evenly placed into the mould using shovels, and vibrated to the same height as the edges to ensure appropriate thickness of the panels was achieved. After casting, the panels were covered with wet hessian and then plastic sheets were placed over the top. The concrete cylinders, cast simultaneously, were also cured under this same moistcuring condition beside the wall panels. After a period of seven days, the panels and cylinders were removed from the moulds, and stock piled on top of each other where they were allowed to cure under normal shaded conditions until testing.

As indicated in Table 1, the concrete compressive strengths of the various wall panels at day of testing 
varied between $38.0 \mathrm{MPa}$ and $99.3 \mathrm{MPa}$. This indicates a very good range of concrete strengths were obtained for both normal and high strength concrete panels. The variations of concrete strengths for the same batch of concrete are due to the different curing times achieved up to day of testing. Curing ranged from 28 to 91 days which is attributed to availability of laboratory and its associated resources.

\subsection{Test Set-Up}

The actual arrangement of the test set-up is shown in Figure 5. The test frame was designed to support three independent hydraulic jacks each of 80 tonne capacity. The rig was originally built by Doh (2002) consisting of two main steel $310 \mathrm{UC} 118$ columns each $4000 \mathrm{~mm}$ high and 2 steel 380PFC cross beams that support the jacks. The jacks were required to transmit a uniformly distributed load across the top through a steel 250UC72 loading beam at an eccentricity of $t_{w} / 6$. The 250UC supporting beam on the strong floor was identical to the loading beam.

The top and bottom hinged support conditions were each simulated by placing a $23 \mathrm{~mm}$ diameter high strength steel rod on a $50 \mathrm{~mm}$ thick steel plate of $150 \mathrm{~mm}$ width and varying lengths which corresponded to the different test panel dimensions. Two $20 \mathrm{~mm} \times 20 \mathrm{~mm}$ angle sections were clamped to the thick plate using screw bolts. The steel rod was welded along the steel plate at an eccentricity of $t_{w} / 6$ from the section centreline. Details of the simply supported top hinged edge are shown in Figure 5(b). To achieve the hinged side support conditions for two-way action, the edges of the wall panels had to be effectively stiffened in the perpendicular direction to prevent rotation about the $\mathrm{x}$-axis while allowing rotation about the $\mathrm{y}$-axis. To achieve this, two 150 PFC's separated by a square hollow section extending along the height of both sides of the test panel were used [see Figure 5(c)]. The side restraints were tied up with high tension bolts (D16@100) through the SHS, to take advantage of the stronger axis of the section.

Dial gauges were used to measure the lateral deflections of the wall panels during testing. The positioning of the dial gauges for the wall panels with one opening are indicated in Figure 6(a). For the wall panels with one opening, all dial gauges were positioned midway between the edges of the panel and the edges of the opening. For the wall panels with two openings, the top, bottom and side gauges were all positioned midway between the edges of the panel and the edges of the opening as shown in Figure 6(b). The final dial gauge was placed in the very centre of the panel as shown.

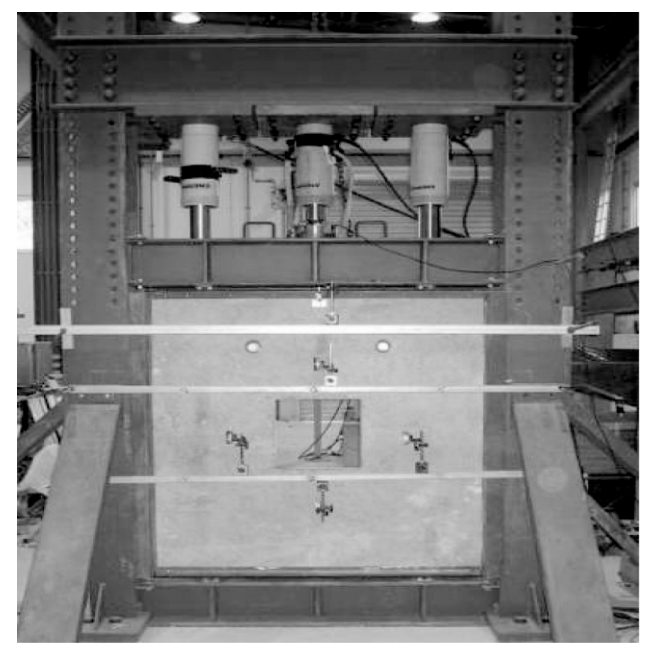

(a) Test frame arrangement

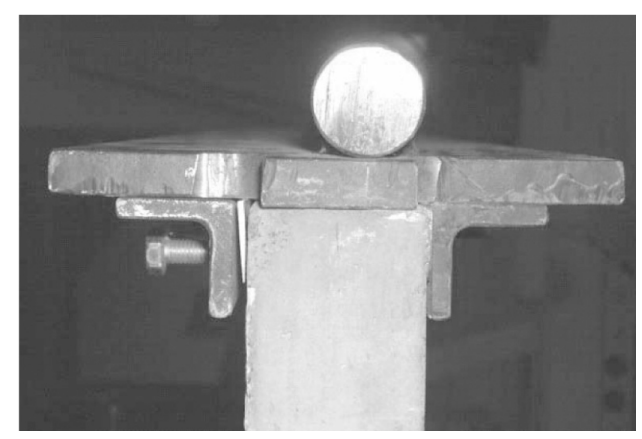

(b) Top and bottom restraint

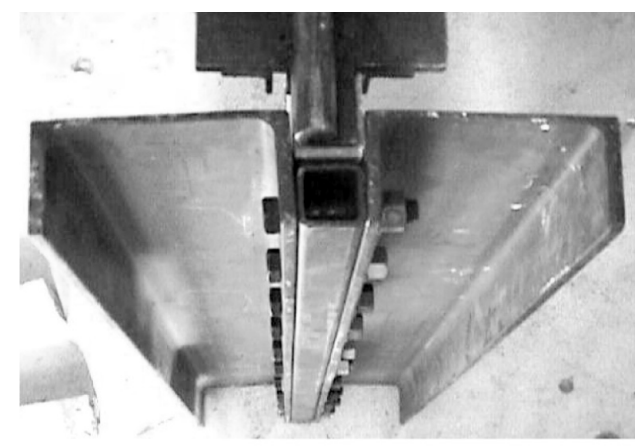

(c) Top view of side restraint

Figure 5. Loading frame and support conditions

\subsection{Test Procedure}

A static loading regime was adopted for the testing. Load increments, utilising the load cell positioned between the centre hydraulic jack and upper loading beam, were applied to the wall panel at approximately 0.5 tonnes per hydraulic jack. The walls were therefore loaded at approximately $14.7 \mathrm{kN}(0.5 \times 3$ tonnes $)$ increments measured by the load-cell up to failure. At each load increment, crack patterns and deflections were recorded. Most of the panels with high strength concrete 


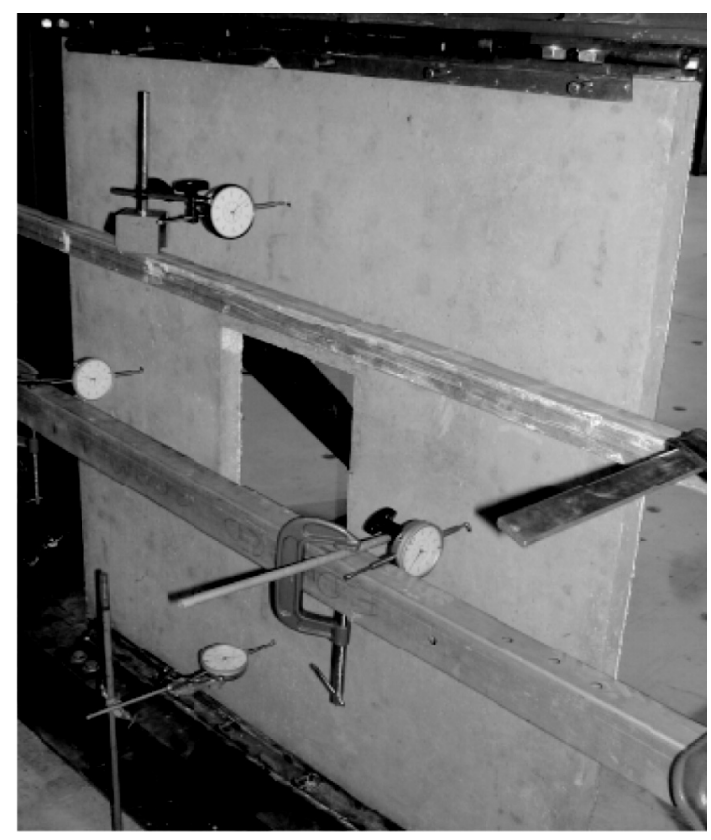

(a) Wall panel with one opening

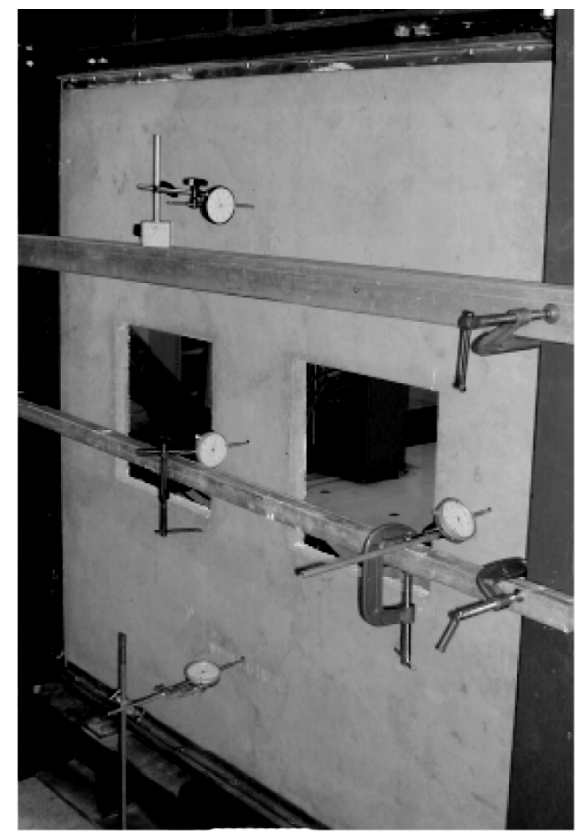

(b) Wall panel with two openings

Figure 6. Dial gauge locations

failed in a brittle mode and the sudden failure of these panels made it sometimes difficult to record the maximum deflection precisely at failure. The ultimate load was accurately recorded using the load cell output, with values indicated in Table 1.

\section{RESULTS}

\subsection{Crack Patterns}

Figures 7 to 14 show the crack patterns observed on a typical selection of test panels after failure. These panels give an indicative insight of cracking behaviour observed.



Figure 7. Crack pattern on compression face of O50W1C1.2
The one-way panels with openings, in Figures 7 to 10, showed typical single curvature bending failure characterised by horizontal cracking at the centre of the panels, similar to the ideal scenarios of Figure 1(a). This was evident irrespective of whether one or two openings were present. There are distinct differences in failure modes of corresponding normal and high strength wall panels. The high strength panels (Figures 8 and 10) seemed to have a more brittle failure mode pattern with a distinctive single crack evident at failure whereas the normal strength

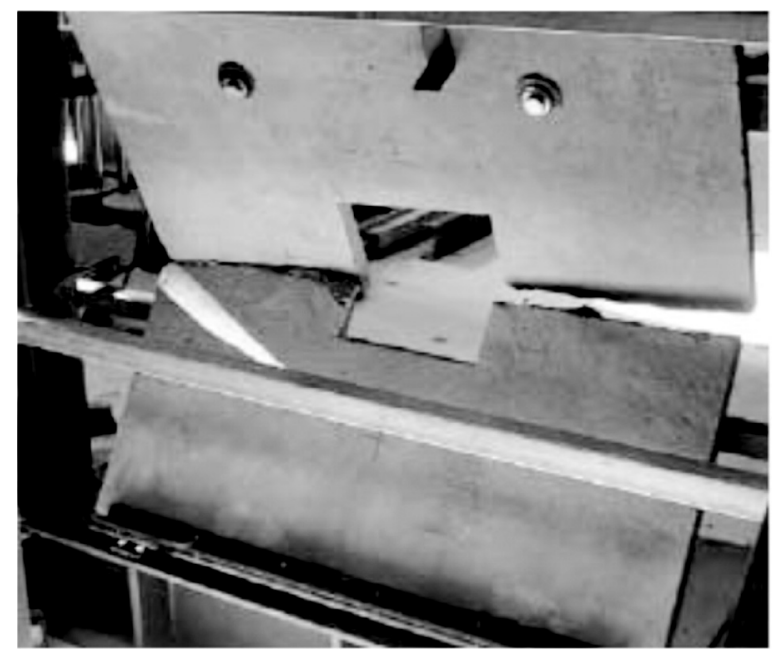

Figure 8. Crack pattern on compression face of O90W1C1.2 


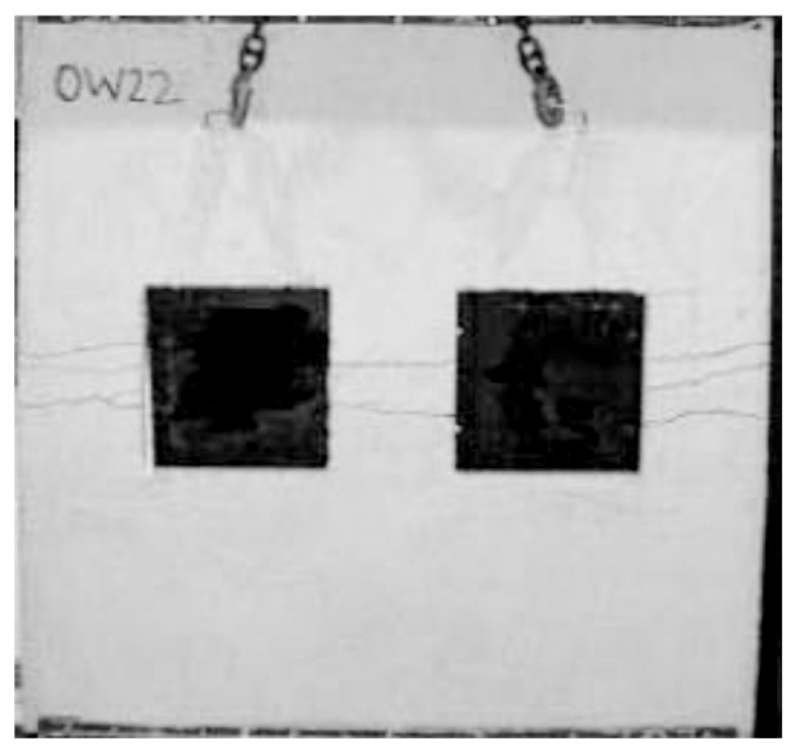

Figure 9. Crack pattern on tension face of O50W2C1.6

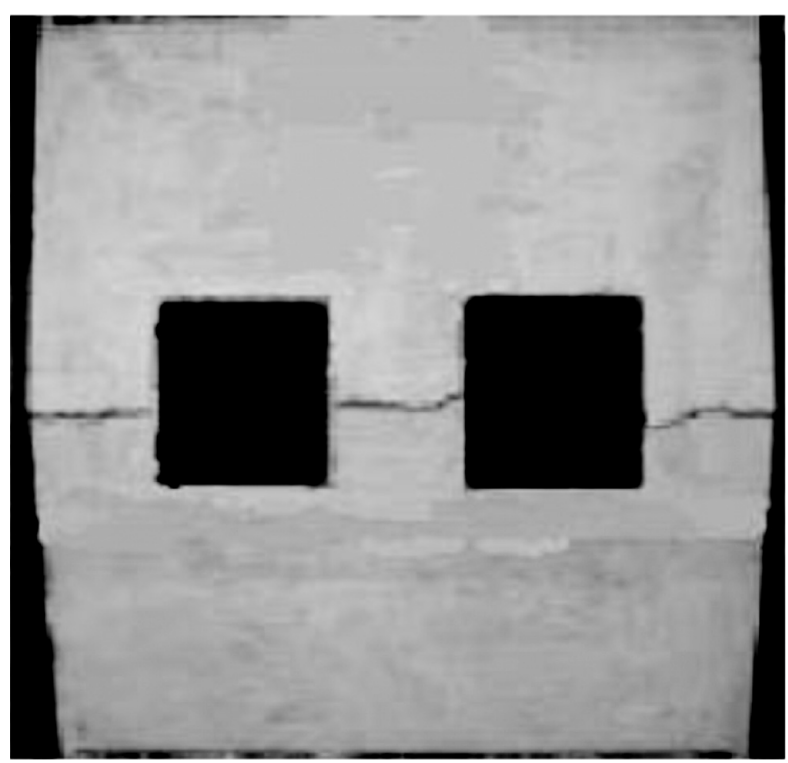

Figure 10. Crack pattern on tension face of O90W1C1.2

panels (Figures 7 and 9) seemed to produce several bending cracks before concrete failure at the midheight of the wall panels. Typically, explosive types of failures were observed for all panels, more so in the high strength panels.

The two-way panels in Figures 11 to 14 with openings showed typical double curvature bending failure characterised by diagonal cracking from corners that make their way to corner edges of openings, similar to the ideal scenario of Figure 1(b). This was evident irrespective of whether one or two openings were present. In addition the panels with two openings (Figures 13 and 14) produced a horizontal crack pattern

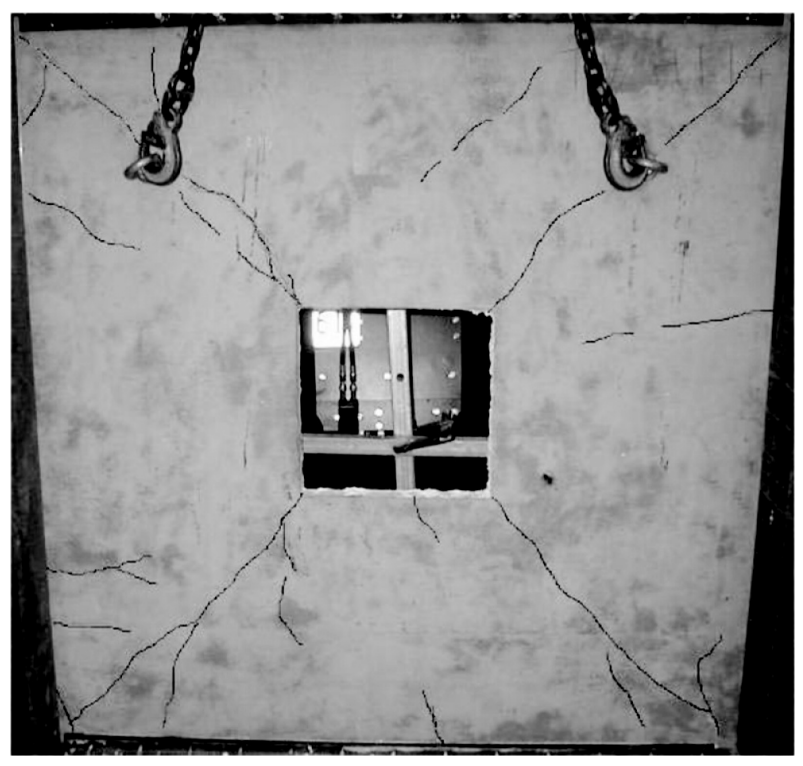

Figure 11. Crack pattern on tension face of T45W1C1.4

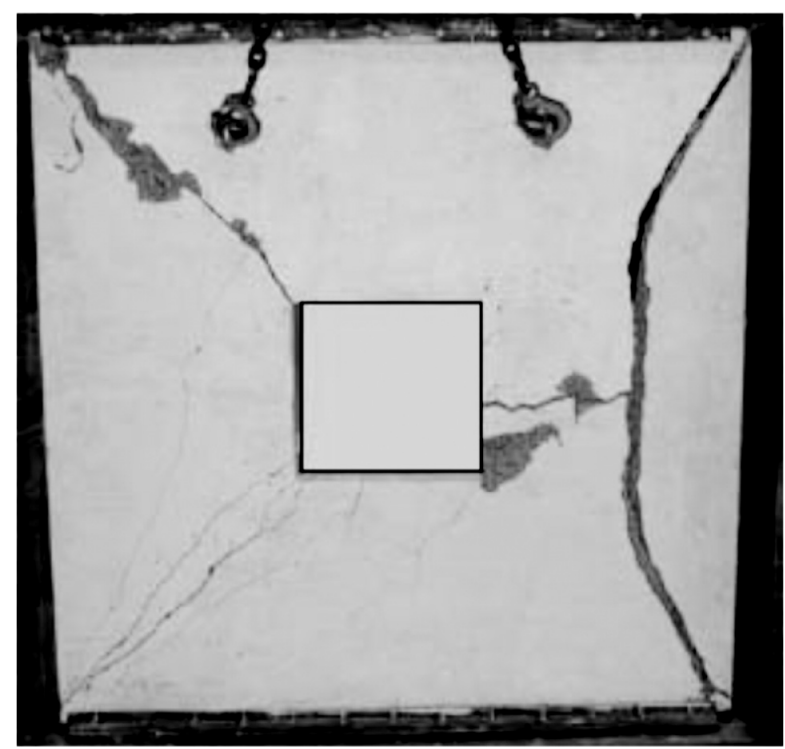

Figure 12. Crack pattern on tension face of T90W1C1.4

in the column sections only, which is logical since this is the area where the cross-section is reduced. Failure in this region could become the dominating factor in axial load capacity.

The distinct differences in failure modes for panels of different strengths is again noted, with high strength panels (Figures 12 and 14) again producing distinct brittle cracks whereas more smeared diagonal cracks were evident in normal strength panels (Figures 11 and 13). It should also be noted that the diagonal crack patterns do deviate a little depending on wall irregularities and loading but the anticipated crack pattern was generally achieved in most cases. 




Figure 13. Crack pattern on tension face of T45W2C1.4



Figure 14. Crack pattern on tension face of T90W2C1.4

\subsection{Deflection}

Typical load versus lateral deflection relationships for the wall panels tested in both one and two-way actions are shown in Figures 15 to 22. They show that the deflections at the wall centre are generally in proportion to adjacent points. That is, load deflection paths for left and right transducers are similar, as are readings for top and bottom transducers in these figures. This indicates the data gives a reasonably accurate indication of load versus lateral deflection measurement.

The curves for the one-way action panels with openings (see Figures 15 to 18 ) give a very good indication of load deflection characteristics acting in single curvature. This is typified by the maximum

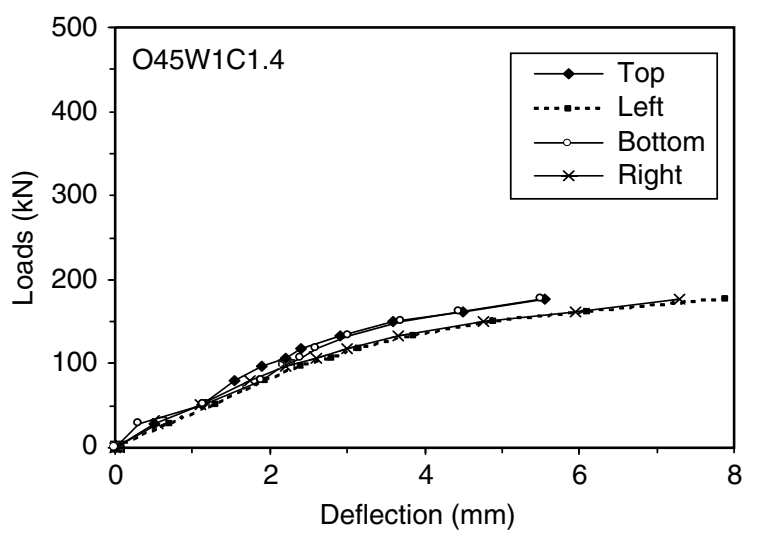

Figure 15. Load versus lateral deflection curves for O45W1C1.4

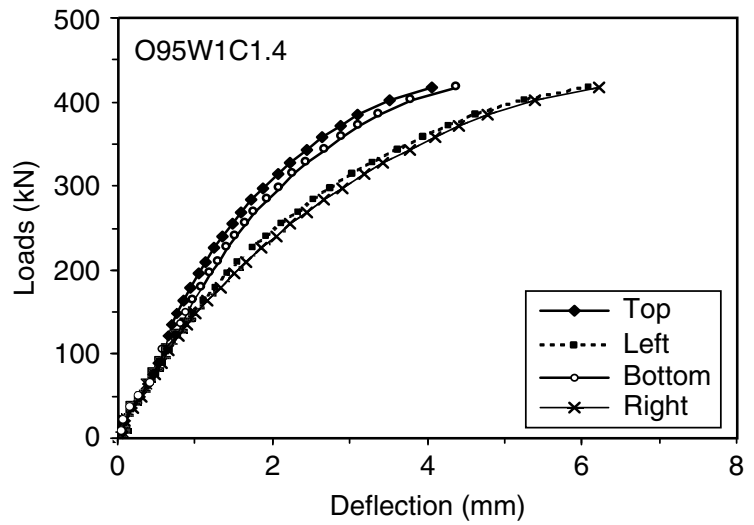

Figure 16. Load versus lateral deflection curves for wall O95W1C1.4

deflection readings occurring in the left and right transducers that are located on the central horizontal axis. It is also interesting to compare deflection profiles of identical normal and high strength concrete panels. The normal strength curves (Figures 15 and 17) tended to show a more nonlinear load-deflection path early in their load history whereas high strength panels (Figures 16 and 18) showed a more linear load-deflection path early before becoming nonlinear. The difference in behaviour is also highlighted by the fact that normal strength panels being had deflections at least double those of the high strength counterparts for the same load level.

Figures 19 and 20 highlight typical load-deflection of two-way action walls with one opening. The increase in nominal strength, from $45 \mathrm{MPa}$ to $90 \mathrm{MPa}$, clearly shows that the load-deflection path becomes more linear at early load levels before becoming nonlinear (see Figure 20). This early linear path is not evident in the normal strength panel behaviour given in Figure 19. Figures 21 and 22 are the load-deflection 


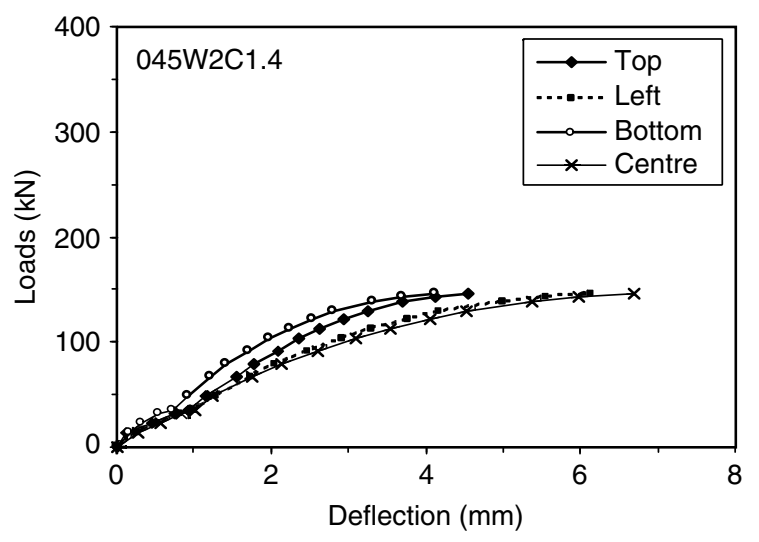

Figure 17. Load versus lateral deflection curves for O45W2C1.4

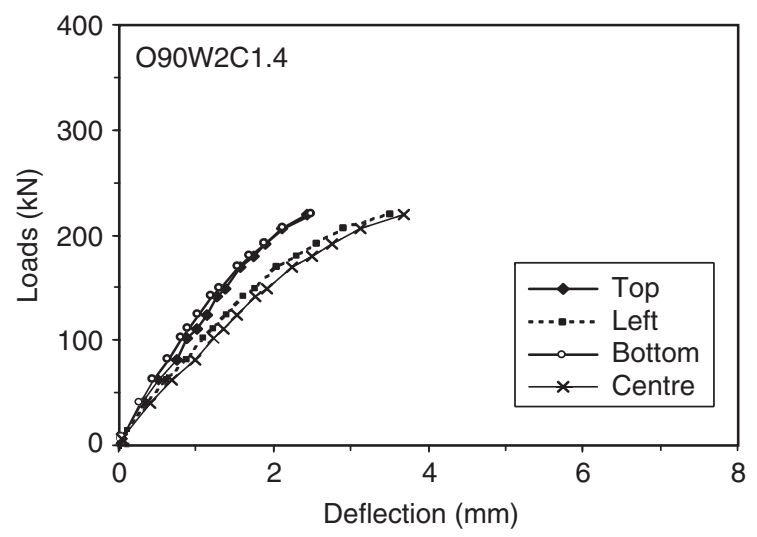

Figure 18. Load versus lateral deflection curves for wall O90W2C1.4

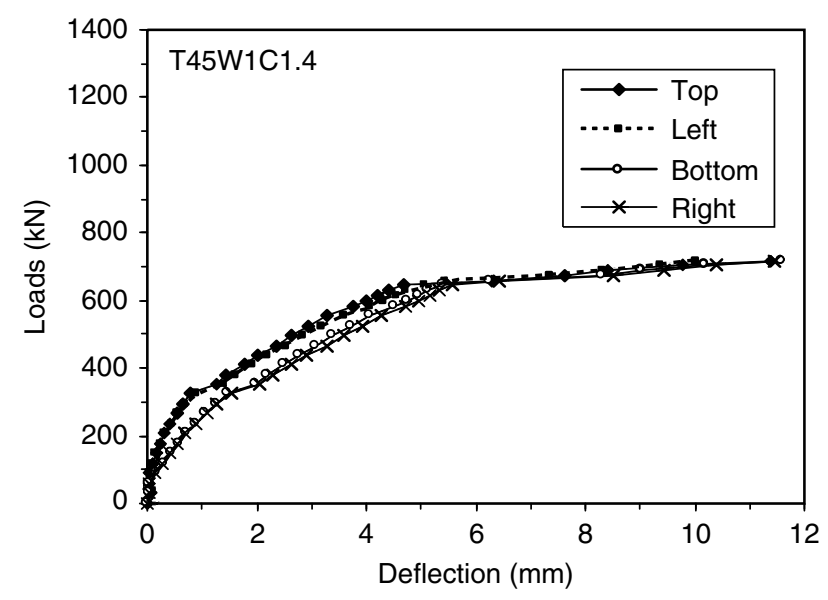

Figure 19. Load versus lateral deflection curves for T45W1C1.4

paths of two-way action walls with two openings. Again the increase in concrete strength, from $45 \mathrm{MPa}$ to $90 \mathrm{MPa}$, resulted in more linear load-deflection path

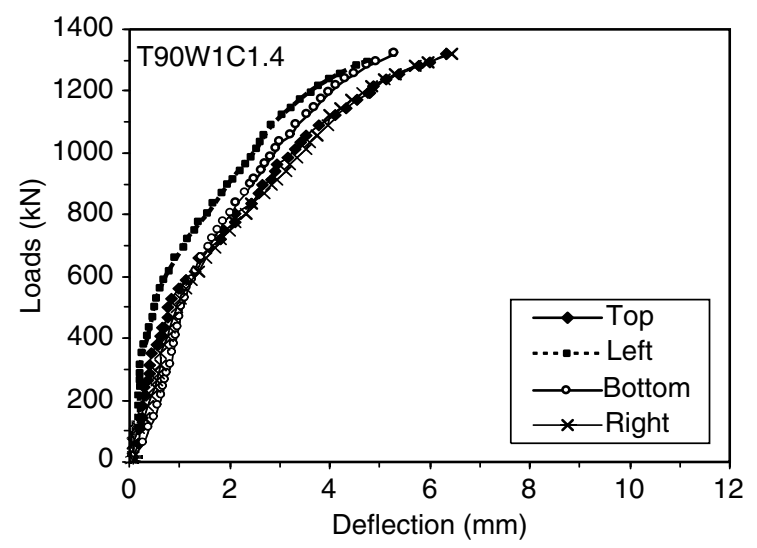

Figure 20. Load versus lateral deflection curves for wall T90W1C1.4

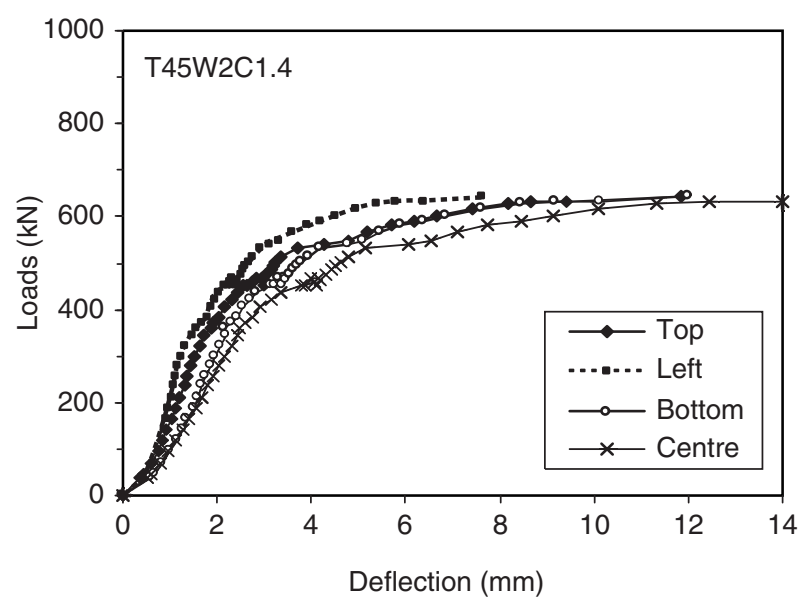

Figure 21. Load versus lateral deflection curves for T45W2C1.4

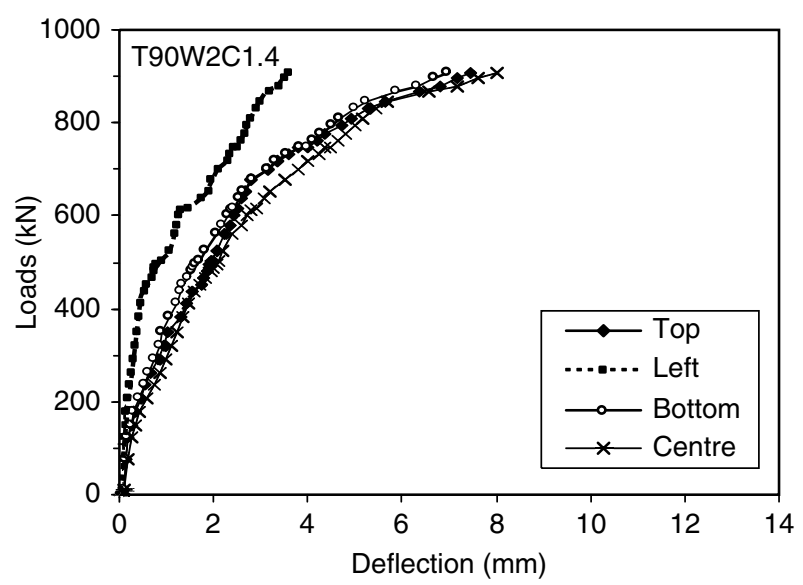

Figure 22. Load versus lateral deflection curves for wall T90W2C1.4

at early load levels. The effect of two openings compared to one is clearly evident where greater deflections have occurred for the same load levels. For 
example at a load level of $800 \mathrm{kN}$, deflections of around $2 \mathrm{~mm}$ were achieved in T90W1C1.4 (see Figure 20) whereas deflections of around $4 \mathrm{~mm}$ were achieved in T90W2C1.4 (see Figure 22).

The distinct advantages of these two-way action panels compared to counterpart one-way walls is also evident with less deflections being achieved in the later case, for the same load level. This can be highlighted in a direct comparison between Figures 16 and 20 which illustrate the behaviour of similar high strength concrete panels supported on two and four respectively. For example a load level of $400 \mathrm{kN}$ gives a lateral deflection of $4 \mathrm{~mm}$ for the one-way action panel and $1 \mathrm{~mm}$ for the two-way action panel, highlighting the impact of the additional side restraints.

\subsection{Actual and Predicted Failure Loads}

The ultimate loads, $N_{\text {u.test }}$ and the axial strength ratios, $N_{\text {u.test }} / f_{c}^{\prime} L_{\text {eff }} t_{w}$, together with the concrete strengths for all the test panels are given in Table 1. Interestingly even though panels have high slenderness ratios and have either one or two central openings, there still is significant ultimate load capacity recorded in all cases. Further the failure loads for the two-way panels are much higher, by approximately 2 to 4 times, than the corresponding one-way specimens, clearly illustrating the advantage of having panels supported on all sides. The reduced strengths of walls with two openings compared to identical walls with one opening is also evident. For example, O95W2C1.2 (two openings) failed at $308.1 \mathrm{kN}$ whereas O95W1C1.2 (one opening) failed at $488.5 \mathrm{kN}$; similarly T70W2C1.6 failed at $988.8 \mathrm{kN}$ compared to T70W1C1.6 which failed at $1390.6 \mathrm{kN}$.

Axial strength ratios $\left(N_{\text {u.test }} / f_{c}^{\prime} L_{\text {eff }} t_{w}\right)$ also provided in Table 1 reveal further interesting trends. For panels in one-way action this ratio tends to decrease with an increased slenderness ratio. This is generally not true for two-way panels where no specific trend is evident with increased slenderness. More significantly, the axial strength ratios for the two-way panels (ranging from 0.321 to 0.512 ) are significantly higher than those for the one-way panels (ranging from 0.089 to 0.175 ) which again indicate the distinct advantage of having panels supported on all sides.

Table 2 shows predicted failure for test panels using Eqns 1 and 3, along with ratios of predicted to test results. Eqn 1 gives variable and at times unsatisfactory failure load predictions. For example predicted load capacity of one-way panels with slenderness ratios of 35 or 40 reveals zero capacity. This is obviously not the case as actual test results produced significant load capacity for these panels. For two-way panels Eqn 1 predictions were in closer agreement to actual failure loads. Note that AS3600 Eqn 1 can be used for two-way panels with openings, as long as area of openings do not exceed $1 / 10$ of total wall area (see last paragraph of section 2). This rule was slightly exceeded for two-way panels with two openings (area of openings $=1 / 8$ of wall area), but predictions for these cases were calculated in any case. Eqn 3 gives much better overall failure load predictions for all one-way and twoway panels tested. Recall it caters for walls with openings and was derived for higher slenderness ratios, various concrete strengths and support conditions.

Observation of predicted/test ratios in Table 2 further highlights the reliability of prediction Eqn 3 . For one-way panels (with one or two openings) the average ratio, $N_{u E q 3} / N_{u, t e s t}$, is 1.00 with a standard deviation of 0.13 . Similarly for two-way panels (with one or two openings) the average ratio is 0.94 with standard deviation of 0.09 . This indicates very good prediction of failure load, with slight over-estimation occurring at times. If an appropriate strength reduction, $\phi$, factor is used in design (eg. $\phi=0.6$ in AS3600), over-estimation will not occur. Eqn 1 produced an acceptable average ratio $\left(N_{u E q 1} / N_{u, \text { test }}\right)$ for the two-way panels of 0.89 with higher standard deviation of 0.18 , but gave totally unacceptable ratios in the range of 0.0 to 0.36 for one-way panels.

This analysis further verifies and illustrates the applicability of Eqn 3 originally presented by Doh and Fragomeni (2006). Recall the equation was originally derived for eight normal strength concrete walls with openings that had high slenderness with varying support conditions. Eqn 3 has now been found to perform adequately for a larger range of one and twoway panels with both normal and high strength concrete in this study. It was also found to perform satisfactorily against wall panel test data by Saheb and Desayi (1990).

\section{FURTHER VERIFICATION AND DISCUSSION}

In an effort to make Eqn 3 more encompassing another stage of testing of twelve wall panels was undertaken by Lee (2008), where window openings of varying configurations were placed at varying locations and also where door type openings existed. Figure 23 and Table 3 give details and failure load results of the wall panels tested. All panels were identically sized with $H / t_{w}=30$, and F41 mesh placed centrally within the wall crosssection. Again the reinforcement ratios $\rho_{v}$ and $\rho_{h}$ were 
Table 2. Predicted and actual failure loads of panels with one or two openings

\begin{tabular}{|c|c|c|c|c|c|c|c|c|}
\hline $\begin{array}{l}\text { Panel } \\
\text { designation }\end{array}$ & $\begin{array}{l}\text { Size of panel } \\
H \times L \times t_{w}(\mathrm{~mm})\end{array}$ & $\begin{array}{c}\text { Opening size } \\
H_{0} \times L_{0} \times n(\mathrm{~mm})\end{array}$ & $H / t_{w}$ & $\begin{array}{c}N_{u, t e s t} \\
(\mathbf{k N})\end{array}$ & $\begin{array}{c}N_{u E q 1} \\
(\mathbf{k N})\end{array}$ & $\begin{array}{c}N_{u E q 3} \\
(\mathbf{k N})\end{array}$ & $\begin{array}{l}N_{u E q 1} / \\
N_{u, t e s t}\end{array}$ & $\begin{array}{l}N_{u E q 3} / \\
N_{u, t e s t}\end{array}$ \\
\hline O50W1C1.2 & $1200 \times 1200 \times 40$ & $300 \times 300 \times 1$ & 30 & 309.0 & 91.6 & 290.1 & 0.30 & 0.94 \\
\hline O70W1C1.2 & & & & 426.7 & 117.0 & 344.4 & 0.27 & 0.81 \\
\hline O90W1C1.2 & & & & 470.9 & 164.3 & 436.9 & 0.35 & 0.93 \\
\hline O95W1C1.2 & & & & 488.5 & 166.2 & 440.4 & 0.34 & 0.90 \\
\hline O45W1C1.4 & $1400 \times 1400 \times 40$ & $350 \times 350 \times 1$ & 35 & 191.3 & 0 & 213.2 & 0 & 1.11 \\
\hline O90W1C1.4 & & & & 300.2 & 0 & 404.9 & 0 & 1.35 \\
\hline O95W1C1.4 & & & & 426.1 & 0 & 471.0 & 0 & 1.11 \\
\hline O50W1C1.6 & $1600 \times 1600 \times 40$ & $400 \times 400 \times 1$ & 40 & 294.3 & 0 & 286.0 & 0 & 0.97 \\
\hline O90W1C1.6 & & & & 503.3 & 0 & 475.1 & 0 & 0.94 \\
\hline O50W2C1.2 & $1200 \times 1200 \times 40$ & $300 \times 300 \times 2$ & 30 & 191.3 & 57.9 & 185.1 & 0.30 & 0.97 \\
\hline O70W2C1.2 & & & & 242.8 & 78.0 & 227.9 & 0.32 & 0.94 \\
\hline O95W2C1.2 & & & & 308.1 & 110.8 & 291.5 & 0.36 & 0.95 \\
\hline O45W2C1.4 & $1400 \times 1400 \times 40$ & $350 \times 350 \times 2$ & 35 & 150.7 & 0 & 177.7 & 0 & 1.18 \\
\hline O90W2C1.4 & & & & 244.3 & 0 & 268.0 & 0 & 1.10 \\
\hline O95W2C1.4 & & & & 350.8 & 0 & 311.7 & 0 & 0.89 \\
\hline O50W2C1.6 & $1600 \times 1600 \times 40$ & $400 \times 400 \times 2$ & 40 & 195.7 & 0 & 200.7 & 0 & 1.03 \\
\hline O70W2C1.6 & & & & 279.0 & 0 & 260.2 & 0 & 0.93 \\
\hline O90W2C1.6 & & & & 347.3 & 0 & 314.4 & 0 & 0.91 \\
\hline T50W1C1.2 & $1200 \times 1200 \times 40$ & $300 \times 300 \times 1$ & 30 & 706.3 & 673.6 & 676.2 & 0.95 & 0.96 \\
\hline T70W1C1.2 & & & & 953.5 & 992.3 & 886.6 & 1.04 & 0.93 \\
\hline T45W1C1.4 & $1400 \times 1400 \times 40$ & $350 \times 350 \times 1$ & 35 & 732.8 & 636.4 & 725.5 & 0.87 & 0.99 \\
\hline T90W1C1.4 & & & & 1303.7 & 1330.1 & 1215.5 & 1.02 & 0.93 \\
\hline T95W1C1.4 & & & & 1298.4 & 1345.4 & 1225.4 & 1.04 & 0.94 \\
\hline T50W1C1.6 & $1600 \times 1600 \times 40$ & $400 \times 400 \times 1$ & 40 & 1030.1 & 695.3 & 878.5 & 0.67 & 0.85 \\
\hline T70W1C1.6 & & & & 1390.6 & 1038.2 & 1162.9 & 0.75 & 0.84 \\
\hline T90W1C1.6 & & & & 1583.3 & 1293.9 & 1362.7 & 0.82 & 0.86 \\
\hline T50W2C1.2 & $1200 \times 1200 \times 40$ & $300 \times 300 \times 2$ & 30 & 618.0 & 449.1 & 548.9 & 0.73 & 0.89 \\
\hline T70W2C1.2 & & & & 633.4 & 661.6 & 688.7 & 1.04 & 1.09 \\
\hline T90W2C1.2 & & & & 665.1 & 866.9 & 775.5 & 1.30 & 1.17 \\
\hline T45W2C1.4 & $1400 \times 1400 \times 40$ & $350 \times 350 \times 2$ & 35 & 662.2 & 424.2 & 541.5 & 0.64 & 0.82 \\
\hline T90W2C1.4 & & & & 918.2 & 886.7 & 821.1 & 0.96 & 0.89 \\
\hline T95W2C1.4 & & & & 759.9 & 745.9 & 753.4 & 0.98 & 0.99 \\
\hline T50W2C1.6 & $1600 \times 1600 \times 40$ & $400 \times 400 \times 2$ & 40 & 647.5 & 555.7 & 659.2 & 0.86 & 1.02 \\
\hline T70W2C1.6 & & & & 988.8 & 692.1 & 921.2 & 0.70 & 0.93 \\
\hline T90W2C1.6 & & & & 1236.1 & 868.1 & 1175.7 & 0.70 & 0.95 \\
\hline
\end{tabular}

0.0031 for all panels, satisfying the minimum requirements in the Australian Standard. Three reinforcing strips cut from F41 mesh were also placed diagonally in each corner of the openings to prevent shrinkage cracking as before. The testing regime was identical to the panels in the main program (and described in section 4). As before failure loads, crack patterns and deflections were all recorded during testing with full details of results presented elsewhere (Lee 2008). Test panel failure loads and predictions are investigated further here.

Table 3 shows that Eqn 3 over-predicts failure load in 11 of the 12 cases. The over-prediction is more significant in the one and two-way panels that had door openings. Panels with window openings were in closer agreement with test results. The average predicted to test ratio $\left(N_{u E q 3} / N_{u, \text { test }}\right)$ for all panels is 1.11 with standard deviation of 0.16 which also clearly shows slight over-prediction. This indicates that even though Eqn 3 was verified for a number of panels with one or two openings, over-prediction of failure load can occur when openings are offset to the left or right, or up or down from the central wall axes. Lee (2008) has suggested a more encompassing factor ' $\chi_{x y}$ ' to replace ' $\chi$ 'that allows for variations in opening size and location from the horizontal and vertical axes. The factor, $\chi_{\mathrm{xy}}$, requires significantly more test results so that it gets calibrated along with $k_{1}$ and $k_{2}$. Again it should be noted that in design, safe prediction will occur using Eqn 3 in its current form when a strength reduction, $\phi$, factor is used. 

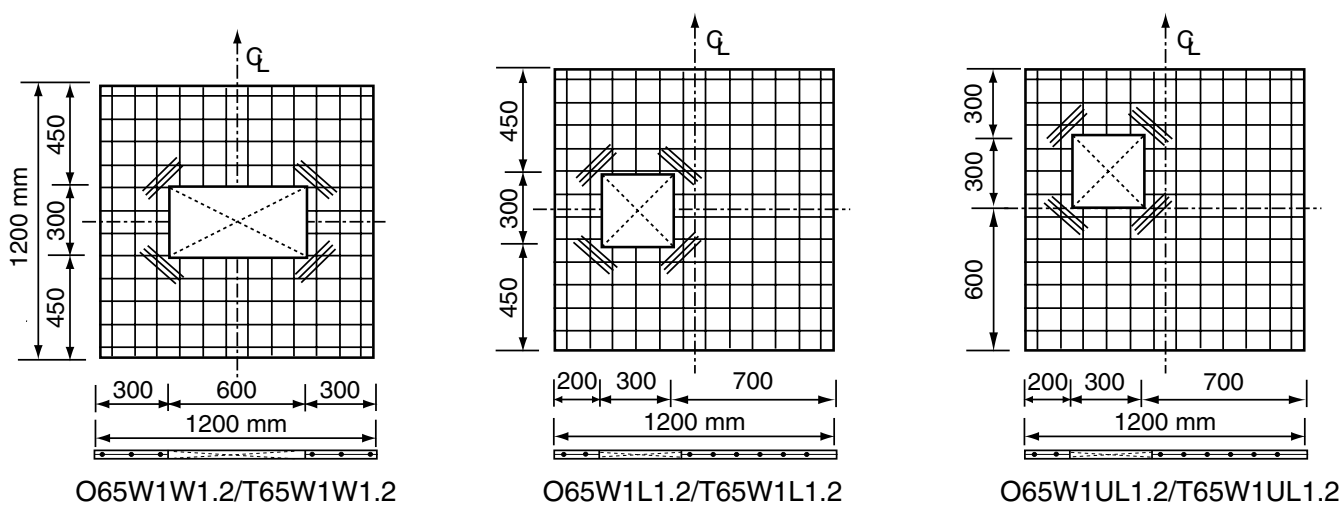





O65D1C1.2/T65D1C1.2

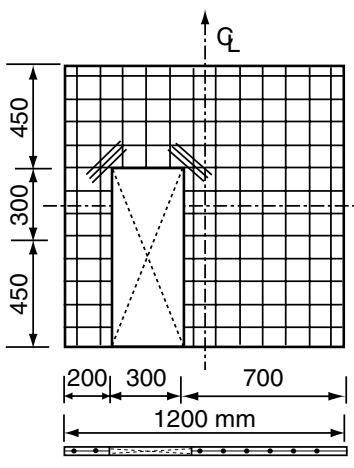

O65D1L1.2/T65D1L1.2

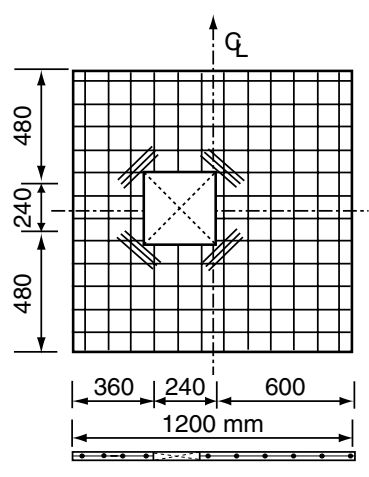

T65W1SL1.2

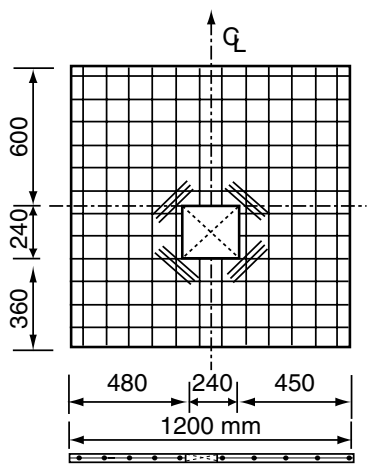

T65W1SB1.2

Figure 23. Details of typical test wall panels with various openings (dimensions in $\mathrm{mm}$ )

Table 3. Predicted and actual failure loads of panels with varying opening configurations

\begin{tabular}{|c|c|c|c|c|c|c|}
\hline $\begin{array}{l}\text { Panel } \\
\text { designation }\end{array}$ & $\begin{array}{l}\text { Size of panel } \\
H \times L \times t_{w}(\mathrm{~mm})\end{array}$ & $\begin{array}{c}\text { Opening size } \\
H_{\mathrm{o}} \times L_{\mathrm{o}} \times n(\mathrm{~mm})\end{array}$ & $\begin{array}{c}\boldsymbol{f}_{c m} \\
(\mathrm{MPa})\end{array}$ & $\begin{array}{c}N_{u, t e s t} \\
(\mathbf{k N})\end{array}$ & $\begin{array}{c}N_{u E q 3} \\
(\mathrm{kN})\end{array}$ & $\begin{array}{l}N_{u E q 3} / \\
N_{u, t e s t}\end{array}$ \\
\hline O65W1W1.2 & $1200 \times 1200 \times 40$ & $300 \times 600 \times 1$ & 60.3 & 176.0 & 210.2 & 1.19 \\
\hline O65W1L1.2 & $1200 \times 1200 \times 40$ & $300 \times 300 \times 1$ & 60.3 & 258.4 & 287.5 & 1.11 \\
\hline O65W1UL1.2 & $1200 \times 1200 \times 40$ & $300 \times 300 \times 1$ & 60.3 & 257.8 & 287.5 & 1.16 \\
\hline O65D1C1.2 & $1200 \times 1200 \times 40$ & $750 \times 300 \times 1$ & 60.3 & 243.7 & 317.6 & 1.30 \\
\hline O65D1L1.2 & $1200 \times 1200 \times 40$ & $750 \times 300 \times 1$ & 60.3 & 206.0 & 287.5 & 1.40 \\
\hline T65W1W1.2 & $1200 \times 1200 \times 40$ & $300 \times 600 \times 1$ & 56.4 & 682.2 & 511.2 & 0.75 \\
\hline T65W1L1.2 & $1200 \times 1200 \times 40$ & $300 \times 300 \times 1$ & 65.0 & 737.5 & 741.6 & 1.01 \\
\hline T65W1UL1.2 & $1200 \times 1200 \times 40$ & $300 \times 300 \times 1$ & 62.4 & 715.7 & 720.7 & 1.01 \\
\hline $\mathrm{T} 65 \mathrm{D} 1 \mathrm{C} 1.2$ & $1200 \times 1200 \times 40$ & $750 \times 300 \times 1$ & 65.0 & 676.9 & 809.6 & 1.20 \\
\hline T65D1L1.2 & $1200 \times 1200 \times 40$ & $750 \times 300 \times 1$ & 56.4 & 582.7 & 671.4 & 1.15 \\
\hline T65W1SL1.2 & $1200 \times 1200 \times 40$ & $240 \times 240 \times 1$ & 62.4 & 794.6 & 834.4 & 1.05 \\
\hline T65W1SB1.2 & $1600 \times 1600 \times 40$ & $240 \times 240 \times 1$ & 56.4 & 721.0 & 755.2 & 1.05 \\
\hline
\end{tabular}

\section{CONCLUSIONS}

An experimental study was undertaken on a total of forty seven reinforced concrete walls with openings in one and two-way action. Loaded with an eccentricity of $t_{w} / 6$, these half-scale specimens had high slenderness ratios between 30 and 40 . The test results indicate that failure loads and crack patterns depend on the opening configuration and support conditions. In effect the failure loads of two-way panels with openings are about 2 to 4 times those of similar one-way panels with openings. Overall, the test results indicate that failure loads decreased when the number of openings was increased from one to two. Further the axial strength ratio for oneway panels gradually decreases when slenderness ratios are increased from 30 to 40 . For two-way panels this axial strength ratio trend was inconclusive.

The Australian Standard (AS3600-2009) wall design equation was found to be inadequate in predicting 
failure load for walls with openings, this is particularly so for one-way walls of high slenderness ratio, where predictions give very conservative or even zero capacity. This is clearly not the case as test results indicate significant capacities can be achieved. The recently derived prediction equation for normal strength concrete walls with openings by Doh and Fragomeni (2006) was also used for comparison in this study. The prediction equation was found to give very good prediction of failure loads for the walls tested and can be extended for use for normal and high strength concrete walls with one or two openings and high slenderness. The equation does tend to slightly over-estimate failure load in some cases where openings are not symmetrical about the wall axes, and therefore further refinement of may be necessary, once further testing is undertaken.

\section{REFERENCES}

ACI318-08 (2008). Building Code Requirements for Reinforced Concrete, American Concrete Institute, Detroit, USA.

AS3600-2009 (2009). Concrete Structures, Standards Australia, Sydney, Australia.

AS3600-2001 (2001). Concrete Structures, Standards Australia, Sydney, Australia.

Doh, J.H., Fragomeni, S. and Kim, J.W. (2001). "Brief review of studies on concrete wall panels in on and two-way action", International Journal of Ocean Engineering and Technology, Vol. 4 No. 1, pp. 38-43.
Doh, J.H. (2002). Experimental and Theoretical Studies of Normal and High Strength Concrete Wall Panels, PhD Thesis, Griffith University, Gold Coast, Australia.

Doh, J.H. and Fragomeni, S. (2005). "Evaluation of experimental work on concrete walls in one and two-way action", Australian Journal of Structural Engineering, Vol. 6, No. 1, pp. 37-52.

Doh, J.H. and Fragomeni, S. (2006). "Ultimate load formula for reinforced concrete wall panels with openings", Advances in Structural Engineering, Vol. 9, No. 1, pp. 103-115.

Fragomeni, S. (1995). Design of Normal and High Strength Reinforced Concrete Walls, $\mathrm{PhD}$ Thesis, University of Melbourne, Australia.

Fragomeni, S. and Doh, J.H. (2010). "Evaluation of the simplified concrete wall design equation in AS3600-2009”, Australian Journal of Structural Engineering, Vol. 10, No. 3, pp. 253-262.

Lee, D.J. (2008). Experimental and Theoretical study of Normal and High Strength Concrete Wall Panels with Openings, PhD Thesis, Griffith University, Australia.

Saheb, S.M. and Desayi, P. (1990). "Ultimate strength of RC wall panels in two-way in-plane action", Journal of Structural Engineering, ASCE, Vol. 116, No. 5, pp. 1384-1402.

Sanjayan, J.G. and Maheswaran, T. (1999). "Load capacity of slender high-strength concrete walls with side supports", ACI Structural Journal, Vol. 96, No. 4, pp. 571-576.

Seddon, A.E. (1956). "The strength of concrete walls under axial and eccentric loads", Symposium on Strength of Concrete Structures, Cement and Concrete Association, London, UK, May. 